\title{
APPLICATION OF ATMOSPHERE SENSING BY INFRARED LIDARS FOR ENVIRONMENTAL PROTECTION AND INDUSTRY NEEDS
}

\author{
V. Švedas 国, V. Vaičikauskas国, and M. Kaučikas曰 \\ ${ }^{a}$ Institute of Physics, Center for Physical Sciences and Technology, Savanoriu 231, LT-02300 Vilnius, Lithuania \\ E-mail: svedas@ktl.mii.lt \\ ${ }^{\mathrm{b}}$ EKSPLA Ltd., Savanoriu 231, LT-02300 Vilnius, Lithuania
}

Received 22 March 2010; revised 6 September 2010; accepted 16 September 2010

\begin{abstract}
The paper analyses some equipment and methodological aspects of atmospheric pollution monitoring by infrared lidars. Features of optical parametric oscillators (including our created two-stage system) operating in the spectral ranges of molecular fundamental vibrations are discussed. The environment protection and industry demands for this remote monitoring technology are considered. Despite the progress in the technology and low detection limits achieved, the reliable and fast identification of pollutants is far from perfection. Inner and outer factors worsening the lidar performance, i. e. stability of the transmitted pulse energy, atmospheric turbulence, and irregularity of the pollutant plume near the source, are examined. A lidaric measurement model implying pulse stability was developed and applied to the $8-14 \mu \mathrm{m}$ and $0.5 \mathrm{~mJ}$ per pulse lidar operating in the topographic target mode with the $0.05 \mathrm{~m}^{2}$ telescope and the mercury cadmium telluride detector. It has been found that the laser pulse energy instability (energy dispersion parameter $D$ ) essentially worsens the detection limit in shorter ranges $(<2 \mathrm{~km}$ for $D=1 \%$ ). Adaptation of lidar technology to the fast varying irregular plumes was tested experimentally. Plume detection events were processed using the probabilistic model, and the probability of false alarm was evaluated.
\end{abstract}

Keywords: IR lidar, atmospheric pollution monitoring, optical parametric oscillator, modelling

PACS: $42.68 . \mathrm{Wt}$, 42.65.Yj, $92.60 . \mathrm{Sz}$

\section{Introduction}

Lidaric sensing is a mature technology of atmospheric pollution monitoring. The ability of remote monitoring of minor atmospheric constituents was demonstrated more than three decades ago [1]. Since then a huge variety of lidar systems operating in the spectral range from the UV to long-wavelength infrared (LWIR, 8-15 $\mu \mathrm{m})$ were developed [2].

A lidar is an innovative component of atmospheric dynamics and chemistry monitoring [3] and of monitoring the major greenhouse gases and criteria pollutants [4] as well as effective tool for solving climatological and meteorological tasks [5]. This remote sensing technology offers real time covering of large urban or country areas. In the case of range-resolved measurement it allows two-dimensional mapping of pollutant plumes. In the petrochemical industries, the monitoring of the leaks of gaseous hydrocarbons is important for preventing loss of raw materials and avoiding explosion hazards [6]. The monitoring of pipeline leaks with the airborn infrared lidar [7] prevents gas losses and pipeline damages due to explosions. Minor leaks $\left(\geq 0.05 \mathrm{~m}^{3} / \mathrm{h}\right)$ can be detected on the flight with this equipment [7]. Remote detection of chemical and biological hazards both of industrial [8] and military origin $[9,10]$ is also possible.

Remote sensors operating in the infrared (IR) region (3-15 $\mu \mathrm{m}$ ) ensure the lowest substance detection limit due to the largest cross-sections of spectral signatures. Additionally, the "fingerprint" region $(8-15 \mu \mathrm{m})$ possesses high specificity advance because of absorption features of the characteristic molecular groups. Despite the achievements there remain some unresolved equipment and methodological issues of IR lidars. Inner and outer factors worsening the lidar performance, i. e. instability of the transmitted pulse energy, atmospheric turbulence, and irregularity of the pollutant plume near the source, are examined in this work. A lidaric measurement model implying the pulse stability was developed. The adaptation of lidar technology to the fast varying plumes was tested experimentally.

Features of lidar laser sources, including those of our developed system, analytical model of remote detection with the IR lidar, and the outer measurement factors, turbulence and pollutant plume irregularity, were 
considered in Section 2. The analytical model was applied to the $8-14 \mu \mathrm{m}$ and $0.5 \mathrm{~mJ}$ per pulse lidar [11] operating in the topographic target mode with the $0.05 \mathrm{~m}^{2}$ telescope and the mercury cadmium telluride detector. The fog jet plume experiment has been carried out to probe the detection of the irregular plume. In Section 3 the environment protection and industry demands for the IR lidar technology are reported.

\section{Equipment and meteorological aspects of remote sensing with the lidar}

A key component of a IR lidar is an appropriate laser operating in the spectral region where target gases possess absorption bands. The lidar transmitter has to follow requirements for the wavelength and spectral bandwidth. The wavelength must be tunable to match appropriate absorption lines or bands of the target molecule and the generation bandwidth should be smaller than the line width of the absorption feature [12].

Long-range laser measurements impose strong requirements for equipment and registration methods. The meteorological effects worsen the propagating beam quality and the lidar performance, respectively. On the other hand, the pollutant plume is not regular but is formed by the changing wind direction and speed. The non-regularity of the received signal and the pollutant plume adds complexity to the lidaric measurement. Moreover, besides the target pollutants (gas or vapour) there are many spectrally interfering compounds which are present in the atmosphere, therefore the scan of the sufficiently wide spectrum is needed for reliable identification of the pollutant.

For more than two decades the $\mathrm{CO}_{2}$ lasers are workhorses of lidaric chemical remote sensors. This is because of the inherently high discharge-to-radiation energetic conversion efficiency of $\mathrm{CO}_{2}$ lasers. This property allows the transmission of the $\sim 100 \mathrm{~mJ}$ LWIR pulses with the repetition rate of hundreds of $\mathrm{Hz}$. The fundamental drawback of $\mathrm{CO}_{2}$ lasers is their discrete lasing spectrum. The use of about twenty of generation lines in the $9-11 \mu \mathrm{m}$ range does not allow performing a continuous spectral scan. With the origin of the sufficiently powerful quantum cascade lasers (QCL) they entered the field of remote sensing. Lidars with QCL transmitters showed the detection limit of about $\sim 1 \mathrm{ppm} \mathrm{m}$ for ozone [13] and $\mathrm{H}_{2} \mathrm{~S}$ [14]. Despite the compactness the deficiency of QCLs is the narrow tuning range. A separate laser should be operated for almost each target gas or vapour. Infrared sources based on the nonlinear conversion of radiation are characterized by the wide tuning range. In turn, the optical parametric oscillator (OPO) sources with the adequate conversion efficiencies ensure tuning capabilities both in the LWIR and in mid-wavelength infrared (MWIR, 3$8 \mu \mathrm{m})$ ranges.

\subsection{OPO laser sources for IR lidars}

The MWIR and LWIR ranges are of primary importance because they carry frequencies of the fundamental molecular vibrations. Absorption cross-sections of fundamental vibrations are by some orders larger than cross-sections of overtone and combination vibrations. Features of parametric oscillators operating in these spectral ranges will be considered in this subsection.

One of the key factors that determines radiation parameters of OPO is a pump source. Nd:YAG lasers, generating $1.064 \mu \mathrm{m}$ wavelength radiation, or higher harmonics of this radiation, are among the most common pump sources. In addition to good energy and spectral properties of these lasers, their high popularity is due to the fact that their technology is well tested, they are reliable and there are many commercially available models of this type of lasers. Dealing with the parametric generator pump pulse duration, the best performance and price ratio is achieved with the nanosecond lasers. Picosecond and femtosecond laser systems are much more expensive. In addition, very short pulse systems are sensitive to external interferences and require frequent maintenance.

As semiconductor diode lasers with the adequate radiation characteristics are becoming available, they are used for pumping solid-state Nd:YAG lasers. Compared to the conventional discharge lamp pumped lasers the diode pumped solid state (DPSS) lasers have exceptional compactness and much higher energetic efficiency. DPSS lasers do not require bulky cooling systems, their service-free operation period is much longer than that of discharge lamps. These are advantages of the DPSS laser pump sources.

However, the replacement of the laser diode or the diode array is expensive and labour-intensive compared to the lamp change process. Thus, to choose a pump source for OPO, it is necessary to take into account the following factors. The lamp pumping is more suitable for tasks that do not require mobility, but high energy is an advantage as in the case of atmospheric pollutant detection. If compactness and rare maintenance are decisive factors, then DPSS laser source is preferable.

Pumping the OPO directly with the $1.064 \mu \mathrm{m}$ wavelength radiation does not provide large efficiency of 
Table 1. Specifications of some tunable OPOs which can be used in the IR lidar applications.

\begin{tabular}{|c|c|c|c|c|c|c|c|c|}
\hline $\begin{array}{c}\text { First cascade } \\
\text { crystal }\end{array}$ & $\begin{array}{l}\text { Tuning } \\
\text { range, } \\
\mu \mathrm{m}\end{array}$ & $\begin{array}{l}\text { Maximum } \\
\text { energy, } \\
\text { mJ }\end{array}$ & $\begin{array}{c}\text { Second } \\
\text { cascade } \\
\text { crystal }\end{array}$ & $\begin{array}{c}\text { Tuning range, } \\
\mu \mathrm{m}\end{array}$ & $\begin{array}{c}\text { Maximum } \\
\text { energy, } \\
\text { mJ }\end{array}$ & $\begin{array}{l}\text { Pulse } \\
\text { repetition } \\
\text { rate, } \mathrm{Hz}\end{array}$ & $\begin{array}{l}\text { Bandwidth, } \\
\mathrm{cm}^{-1}\end{array}$ & Ref. \\
\hline KTP & $1.95-2.2$ & 52 & ZGP & $5-10$ & 0.9 & 30 & 6 & [15] \\
\hline PPKTP & 2.008 & 0.72 & ZGP & $3.3-5.2$ & 0.17 & 20 & very wide & [16] \\
\hline KTP & 2.02 & 43 & $\mathrm{ZGP}$ & $5.5-9.3$ & 1.3 & 30 & no data & [17] \\
\hline KTP & 2.02 & 43 & AGSE & $5.5-10.5$ & 0.32 & 30 & no data & [17] \\
\hline PPLN & $2.3-3.7$ & no data & ZGP & $3.7-10.2$ & 0.023 & $10^{3}$ & $5-6$ & [18] \\
\hline LN & $1.5-4$ & 40 & AGSE & $4-5$ & 2.5 & 100 & no data & [19] \\
\hline KTP & 2.13 & 2.65 & ZGP & $3.7-4.1,4.4-4.8$ & 0.7 & $20 \cdot 10^{3}$ & very wide & [20] \\
\hline KTP & 1.54 & 1.2 & AGSE & 3.71 & 0.12 & $2.5 \cdot 10^{3}$ & no data & [21] \\
\hline KTP & $1.4-1.55$ & 0.1 & AGSE & $3.679-5.71$ & $0.06-0.095$ & 15 & no data & [21] \\
\hline KTP & 1.54 & 1.2 & AGSE & 4 & 0.0187 & $15 \cdot 10^{3}$ & no data & [22] \\
\hline KTA & $2.99,3.18,3.45$ & 50 & CDSE & $4.68-5.12,8.31-10.58$ & 4.5 & no data & no data & [23] \\
\hline KTP & 1.57 & 35 & AGSE & $6.1-14.1$ & 1.1 & 5 & 5 & [24] \\
\hline KTP & 1.57 & $100-120$ & AGSE & 8.5 & 6.8 & 10 & $3.5-5$ & [25] \\
\hline KTP & 1.57 & 100 & AGSE & $8.2-6.8$ & 5 & 10 & $3.5-5$ & [26] \\
\hline KTP & 2.6 & no data & CDSE & 9 & 0.07 & 120 & no data & [27] \\
\hline KTP & $2-2.134$ & 1 & ZGP & $2.9-6.2$ & 0.6 & 5 & no data & [28] \\
\hline KTP & $2.08 ; 2.18$ & $140 ; 80$ & ZGP & $3-5$ & 21 & no data & no data & [29] \\
\hline
\end{tabular}

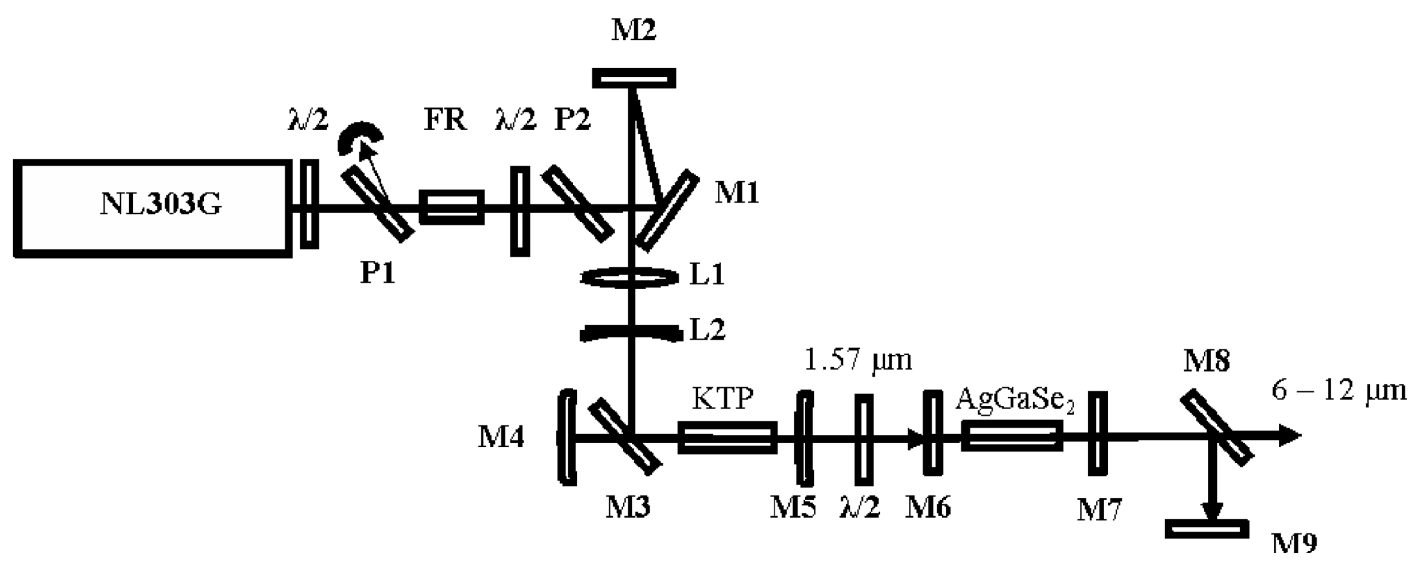

Fig. 1. Experimental layout of the tandem OPO scheme.

parametric generation in the MWIR/LWIR region. Approach of a cascaded two-stage optical parametric generation scheme is employed in this case [15-29]. In the first stage, the OPO incorporating the KTP, KTA, or LN crystals pumped by the Nd:YAG laser generates radiation in the near-infrared (NIR) spectral region. In the second cascade, NIR radiation of the first OPO is used for pumping the second OPO, whose radiation falls within the LWIR region. Such a scheme can be used for the high quality, high nonlinearity $\mathrm{AgGaSe}_{2}, \mathrm{ZnGeP}_{2}$, and CdSe crystals possessing a high damage threshold. Experimentally tested cascaded OPO schemes including wavelengths of stages and used nonlinear crystals are given in Table 1. These parametric sources are potentially suitable for applications in the MWIR/LWIR range lidar systems.
The energy of the common DPSS laser pump source is at a level of a few millijoules. This energy is too low for pumping the bulk crystal based OPO but is sufficient for pumping the periodically poled OPO crystals. The quasi-phase matching in periodically poled crystals [16, 18] ensures larger interaction lengths and smaller parametric generation thresholds as compared to the bulk crystals. The most common periodically poled crystal is oriented lithium niobate (PPLN). High parametric interaction efficiency is achieved in this crystal, even for a low interacting wave intensity.

\subsection{Set-up of LWIR range lidar}

We developed a LWIR lidar transmitter operating in the 6-12 $\mu \mathrm{m}$ range. The mid-IR laser source was 
based on the tandem OPO scheme (Fig. 1). The pump source was a commercial Nd:YAG actively Q-switched nanosecond laser (NL303G, EKSPLA Ltd). This pump laser produced up to $500 \mathrm{~mJ}$ of $1.064 \mu \mathrm{m}$ pulsed (duration 3-6 ns) radiation and the profile of the beam was hat-top. The half-wave plates $\lambda / 2$, polarizers $P 1, P 2$, Faraday rotator $F R$ were applied to avoid back reflections from OPO to the pump laser. Then the radiation was directed to the first OPO cavity by two steering mirrors $M 1$ and $M 2$. The beam diameter was compressed by the telescope consisting of lenses $L 1$ and $L 2$.

The first stage of OPO was based on the KTP $\left(5 \times 5 \times 25 \mathrm{~mm}^{3}\right)$ nonlinear crystal (EKSMA Ltd). The crystal was anti-reflection coated for 1.064 and $1.57 \mu \mathrm{m}$ wavelengths and was cut at $\Theta=90^{\circ}, \varphi=0^{\circ}$ (x-cut). This allowed non-critical phase-matching (II type) at $1.57 \mu \mathrm{m}$ when pumped by $1.064 \mu \mathrm{m}$ radiation. The first stage OPO cavity was singly-resonant for the signal wave. Two sets of mirrors M4 and M5 were used for the first stage OPO. The first set consisted of two flat mirrors. The rear mirror was highly reflective at $1.57 \mu \mathrm{m}$ and no special coatings for other wavelengths were used. The output coupler was highly reflective at the pump wavelength and 50\% reflective at the signal radiation. The second set of mirrors consisted of two spherical mirrors. The radius of the curvature of the concave rear mirror was $40 \mathrm{~cm}$ and that of the convex output coupler was $30 \mathrm{~cm}$. The latter was made as a zero meniscus lens. This choice of mirrors resulted in the unstable positive-branch cavity with the magnification factor $M=1.33$.

The second stage of the tandem OPO system was based on the $\mathrm{AgGaSe}_{2}$ nonlinear crystal $\left(8 \times 10 \times 20 \mathrm{~mm}^{3}\right)$. This crystal was cut for type I critical phase-matching in the $6-12 \mu \mathrm{m}$ range, when pumped at $1.57 \mu \mathrm{m}$. The second stage OPO cavity was also singly resonant for the signal wave $(1.8-2.2 \mu \mathrm{m})$. The cavity consisted of two flat mirrors: the rear mirror was highly transmitting at $1.57 \mu \mathrm{m}$ and highly reflective in the $1.8-2.2 \mu \mathrm{m}$ range, whereas the output coupler reflected $50 \%$ of 1.8 $2.2 \mu \mathrm{m}$ radiation, it was highly transmitting in the 6$12 \mu \mathrm{m}$ range. A separator was placed outside the OPO cavity to separate pump and signal waves from an idler wave. The measured divergence of the idler radiation was $20 \mathrm{mrad}$ at $9 \mu \mathrm{m}$, which corresponded to $M^{2}=$ 16.

The spectral bandwidth of the mid-IR radiation was less than $10 \mathrm{~cm}^{-1}$ in the wavelength tuning range, with typical values of $7-8 \mathrm{~cm}^{-1}$. Although some light molecules possess narrow linewidths $\left(\sim 0.3 \mathrm{~cm}^{-1}\right.$ in the normal atmosphere), however bandwidths of numerous complex molecules are of the order of tens of $\mathrm{cm}^{-1}$. Besides, a moderate bandwidth of the source effectively integrates the background clutter rising from fine structure of atmospheric absorption found in atmospheric windows. Thus, this type of OPO could be regarded as a cost-effective source for spectroscopy of complex molecules of chemical agents.

\subsection{Modelling of the lidaric measurements}

In the lidaric sensing the interrogating laser pulse is transmitted into the open path of interest. Negligible part of the pulse is backscattered by the atmospheric aerosols. The lidar pulse is scattered completely if the beam hits the topographic object. It can be walls of buildings, towers, chimneys, downhills, foliage, water surfaces, etc. Aerosol and topographic photosignals can be separated by the appropriate temporal gates in the registration channel. Part of the pulse is absorbed by the target and the remaining part is scattered mainly in the diffuse mode. The ratio of the scattered radiation power to the hitting one is called the target diffuse reflection coefficient.

The backscattered and collected laser pulse energy is very low, therefore the signal-to-noise ratio (SNR) analysis is a mandatory part of lidaric measurements. On the one hand, the analysis of the noise sources and noise minimization is an important task of the operational characteristics improvement. On the other hand, in the infrared range the topographic photosignal is by many orders larger than the aerosol photosignal. Larger signals give better SNR and, correspondingly, better detection characteristics. Thus, the topographic target illumination is the mostly used mode of MWIR/LWIR lidars.

Aerosol creates a sufficient photosignal for the reliable infrared remote detection and identification in the case of dense and multiphase pollutant plumes. Then simultaneous ranging and spectrochemical analysis become possible with one IR tunable lidar system. So, in [30] the toxic aerosols were identified and their spectral backscatter coefficients were determined with the aid of the discrete wavelength set of the $\mathrm{CO}_{2}$ lidar. In the MWIR range the two-dimensional mapping of hydrocarbon leaks in the oil refinery plumes was done [6]. Our primary goal was to detect as small as possible amount of gas or vapour pollutant in the visibly clear atmosphere, i. e. our basic operation mode is linked with the topographic targets or retroreflectors.

The concentration is not range-resolved in the case of the topographic target. Topographic lidar measurements deliver the path integrated concentration (PIC) of 
the compound [31]. Definition of this parameter is as follows:

$$
\mathrm{PIC}=\int_{0}^{R_{\mathrm{t}}} N(z) \mathrm{d} z,
$$

where $R_{\mathrm{t}}$ is the distance to the target scatterer and $N(z)$ is the distribution of the pollutant concentration along the beam path. The ppm (part-per-million, $10^{-6}$ ) and $\mathrm{ppb}$ (part-per-billion, $10^{-9}$ ) concentration units are employed in this work. In the case of widespread and evenly distributed pollution the needed concentration is the PIC parameter divided by $R_{\mathrm{t}}$. If a pollutant is emitted as a plume, then the average concentration can be obtained from the measured PIC value with the evaluation of the pollutant plume width at the laser beam cross-place.

Experimentally the PIC parameter can be obtained from the spectral records as given below [2]:

$$
\begin{aligned}
\mathrm{PIC}= & \frac{1}{2} \Delta \sigma^{-1}\left[\ln \frac{\varepsilon\left(\lambda_{\text {off }}\right)}{\varepsilon\left(\lambda_{\text {on }}\right)}-\ln \frac{E\left(\lambda_{\text {off }}\right)}{E\left(\lambda_{\text {on }}\right)}\right. \\
& \left.-\ln \frac{\rho\left(\lambda_{\text {off }}\right)}{\rho\left(\lambda_{\text {on }}\right)}\right] .
\end{aligned}
$$

Here all parameters on the right side depend on the wavelength $\lambda$. The differential absorption coefficient is $\Delta \sigma=\sigma\left(\lambda_{\text {on }}\right)-\sigma\left(\lambda_{\text {off }}\right) . E(\lambda)$ is the transmitter pulse energy, $\varepsilon(\lambda)$ is the collected backscattered energy, and $\rho(\lambda)$ is the target reflection coefficient. The indices on and off in Eq. (2) correspond to wavelengths of the molecule absorption maximum and minimum, respectively. According to the recommendations for testing and evaluation of lidar detectors [32], the spectra of reflection coefficients of selected targets have to be measured at the working wavelengths and included into the lidar database prior to the plume detection.

As a rule, the reference optical channel with the reference photodetector are incorporated into a lidar scheme to measure the transmitted pulse energy $E$. Then, the returned and transmitted pulse energies are not recorded separately but the ratio of energies $\varepsilon / E$ is digitized. Then the integrated concentration is

$$
\begin{aligned}
\mathrm{PIC}= & \frac{1}{2} \Delta \sigma^{-1}\left[\ln \frac{\varepsilon\left(\lambda_{\text {off }}\right)}{E\left(\lambda_{\text {off }}\right)}-\ln \frac{\varepsilon\left(\lambda_{\text {on }}\right)}{E\left(\lambda_{\text {on }}\right)}\right. \\
& \left.-\ln \frac{\rho\left(\lambda_{\text {off }}\right)}{\rho\left(\lambda_{\text {on }}\right)}\right] .
\end{aligned}
$$

Two parameters $(\varepsilon / E$ and $\rho$ ) should be measured at two wavelengths. The normalization of return energy to the reference signal magnitude considerably improves the reproducibility of measurement. This is because the collected energy is highly correlated with the reference photosignal. As an example, the correlation coefficient between the received photosignal and the reference photosignal of our IR lidar [11] can exceed 0.95 under the favourable conditions of a shorter range and the negligible atmospheric turbulence.

Further the detection limits of the lidaric sensor will be determined by analysing the values of the informative photosignal and all photodetector noise sources. For the SNR analysis it is practical to operate with the laboratory spectral analysis parameters, that is, transmittance and absorbance. By neglecting absorption at $\lambda_{\text {off }}$ the transmittance $T$ of an open path can be written as

$$
T=\exp (-2 \cdot \Delta \sigma \cdot \mathrm{PIC}) .
$$

The dimensionless neperian absorbance $\mathrm{Abs}=-\ln T$ is linearly related to the target pollutant concentration:

$$
\mathrm{Abs}=2 \cdot \Delta \sigma \cdot \mathrm{PIC} .
$$

According to the spectral analysis conventions, for reliable detection of the substance the analytical signal has to exceed the photocurrent noise level threefold, that is,

$$
\mathrm{SNR}>3 .
$$

On the other hand, SNR is the ratio of the photosignal current to the noise current. The photocurrent is the product of the detector responsitivity $r$ and the power $P$ of the collected radiation. Thus, the informative photosignal is $r P$. Abs. Photocurrent is the source of the shot noise [2]. In addition to the photocurrent the dark current and the Johnson's thermal noise are always present in the signal [2]. These two dark noise factors are included in the list of detector specifications as the noise equivalent power (NEP) parameter.

There also exists one more kind of noise which is rarely taken into consideration. This noise stems from the laser pulse-to-pulse energy irreproducibility. In the case of the frequency modulated diode laser spectroscopy this noise was included in the relative intensity noise (RIN) term [33]. In the pulsed lidar applications this term is proportional to the transmitted pulse energy instability. Pulse instability is characterized by the energy dispersion parameter $D$. Thus, the magnitude of the photocurrent noise caused by the pulse energy dispersion is $D \cdot r P$.

It is useful to define the noise equivalent current (NEC) parameter as NEC $=$ NEP $\cdot r$. Then, with the $\tau$ time constant of registration, the electron charge $e$, and 
the number of the collected pulses $n$, the noise current can be expressed as

$$
\text { n.c. }=\left(\left(\mathrm{NEC}^{2} / \tau+2 e r P / \tau+D^{2} r^{2} P^{2}\right) / n\right)^{0.5} \text {. }
$$

In Eq. (7) the first term is the dark noise, the second term is the shot noise, and the third term expresses a laser pulse energy instability contribution to the total noise. With the introduced notations the SNR parameter can be expressed as

$$
\mathrm{SNR}=\frac{r P \cdot \mathrm{Abs}}{\sqrt{\left(\mathrm{NEC}^{2} / \tau++2 e r P / \tau+D^{2} r^{2} P^{2}\right) / n}} .
$$

The lidar performance is largely determined by the returned and collected pulse energy value. The larger collected energy, the better is the SNR and the lower is the detection limit. The collected laser pulse energy $\varepsilon$ is a product of the transmitted pulse energy $E$, the lidar telescope mirror area $A$, the reflection coefficient of the topographic target $\rho$, divided by the square of the range:

$$
\varepsilon=\frac{E A \rho}{\pi \cdot R^{2}} .
$$

For simplicity, in Eq. (9) the absorption by the pollutant is neglected. Neglected absorption is the desired case of low concentrations at the detection limit. The power of collected radiation $P$ needed for the SNR calculation is $E$ divided by the laser pulse duration which is taken optimal, that is, equal to the registration constant $\tau$.

Equations (5), (6), and (8) give the needed lidar capacity as a function of range. In the modelling the $7 \cdot 10^{-3} \mathrm{ppm}^{-1} \mathrm{~m}^{-1}$ differential absorption coefficient was taken. Values of the parameters $E, r, \operatorname{NEC}, \tau, D$, $A$, and $\rho$ included in the calculation are $0.5 \mathrm{~mJ}, 1 \mathrm{~A} / \mathrm{W}$, $5 \cdot 10^{-11} \mathrm{~A} / \mathrm{Hz}^{1 / 2}, 10 \mathrm{~ns}, 1 \%, 0.05 \mathrm{~m}^{2}$, and 0.3 , respectively. The range dependence of the detection limit expressed in the form of PIC $\cdot(n)^{0.5}$ is shown in Fig. 2.

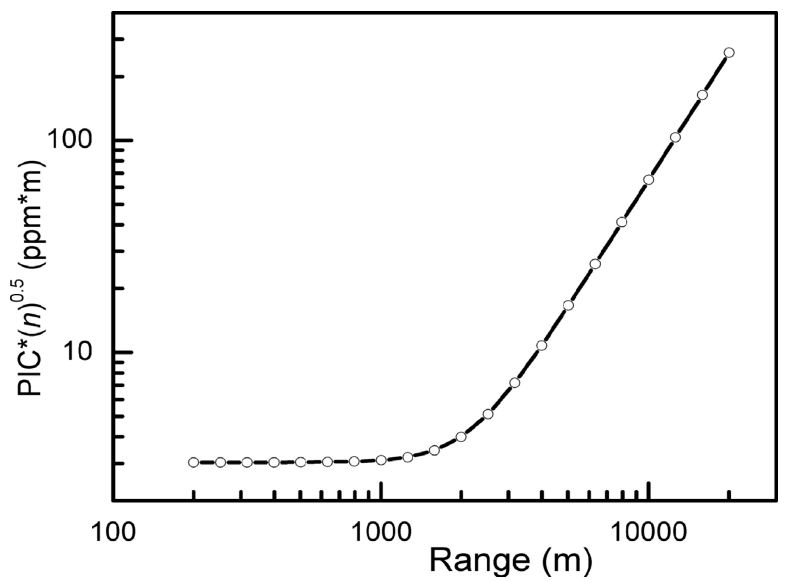

Fig. 2. The calculated detection limit dependence on range.
Calculations show the invariable detection limit in the shorter ranges to $\sim 2 \mathrm{~km}$. Constancy of the detection limit expresses the dominance of the $D^{2} r^{2} P^{2}$ pulse energy fluctuation term in the noise sum (Eq. (7)). In the ranges larger than $2 \mathrm{~km}$ the dark noise term $\mathrm{NEC}^{2} / \tau$ exceeds the other terms and the PIC $\cdot(n)^{0.5}$ grows with the range as $R^{2}$. In the short ranges the PIC $\cdot(n)^{0.5}$ value is $3 \cdot(n)^{0.5} \mathrm{ppm} \cdot \mathrm{m}$. Assuming the $100 \mathrm{~m}$ plume width the $3 \mathrm{ppb}$ detection limit can be obtained by averaging $n=100$ pulses. The detection limit of the lower ppb level satisfies the needs of hazardous chemical vapour sensing. Most hazardous chemicals are harmful at the concentration levels of tens to hundreds ppb [34].

Calculations of the detection limit prove the significance of the laser pulse energy stability and the necessity of proper rationing of transmitter output to the reference photosignal. The taken $1 \%$ value of the transmitted energy fluctuation is low. It is hardly achievable without the transmitted pulse rationing. Fluctuations of the bare OPO output are usually in the range of tens of percent. Thus, rationing of the transmitted pulse is a necessary measure for the lidar performance improvement. This remedy reduces the effective $D$ value by one order of magnitude and reduction of $D$ increases the SNR and decreases the detection limit in the same proportion.

Fluctuations of the lidar transmitter output are the inner factors influencing the performance of remote sensing. Along with inner factors a set of the outer factors should be considered.

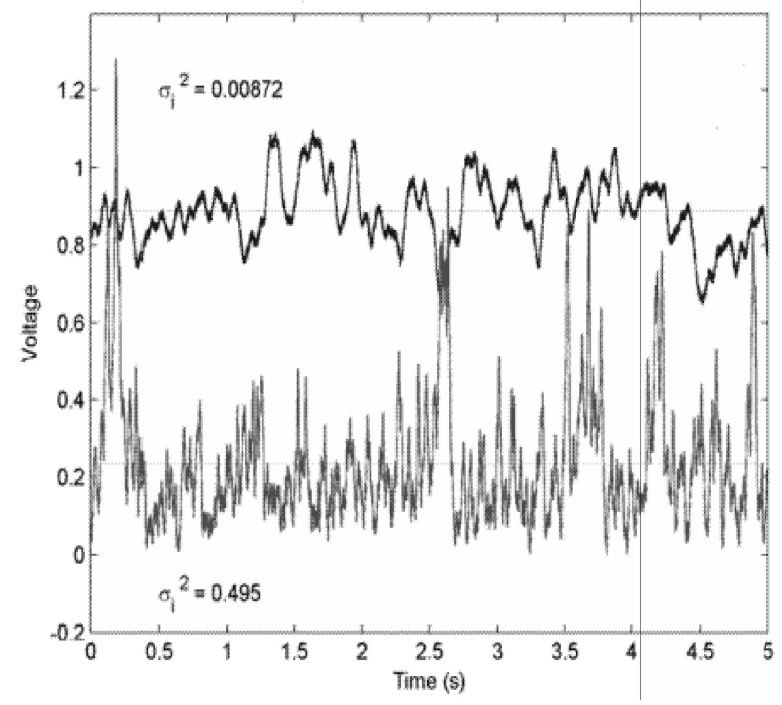

Fig. 3. Atmospheric turbulence data for July 18, 2003 at 6:30 AM (upper record) and 1:05 PM (lower record) [14]. 
Table 2. Potential detection limits for air pollutants using infrared DIAL [40].

\begin{tabular}{lcc}
\hline \multicolumn{1}{c}{ Pollutant } & Detection limit, $\mu \mathrm{g} / \mathrm{m}^{3}$ & Detection range, $\mathrm{m}$ \\
\hline Acetylene $\left(\mathrm{C}_{2} \mathrm{H}_{2}\right)$ & 50 & 800 \\
Ethane $\left(\mathrm{C}_{2} \mathrm{H}_{6}\right)$ & 20 & 800 \\
Ethylene $\left(\mathrm{C}_{2} \mathrm{H}_{4}\right)$ & 10 & 800 \\
Higher alkanes $(\mathrm{C} x \mathrm{H} x)$ & 40 & 800 \\
Hydrogen chloride $(\mathrm{HCI})$ & 20 & 1000 \\
Methane $\left(\mathrm{CH}_{4}\right)$ & 50 & 1000 \\
Methanol $\left(\mathrm{CH}_{3} \mathrm{OH}\right)$ & 200 & 500 \\
Nitrous oxide $\left(\mathrm{N}_{2} \mathrm{O}\right)$ & 100 & 800 \\
\hline
\end{tabular}

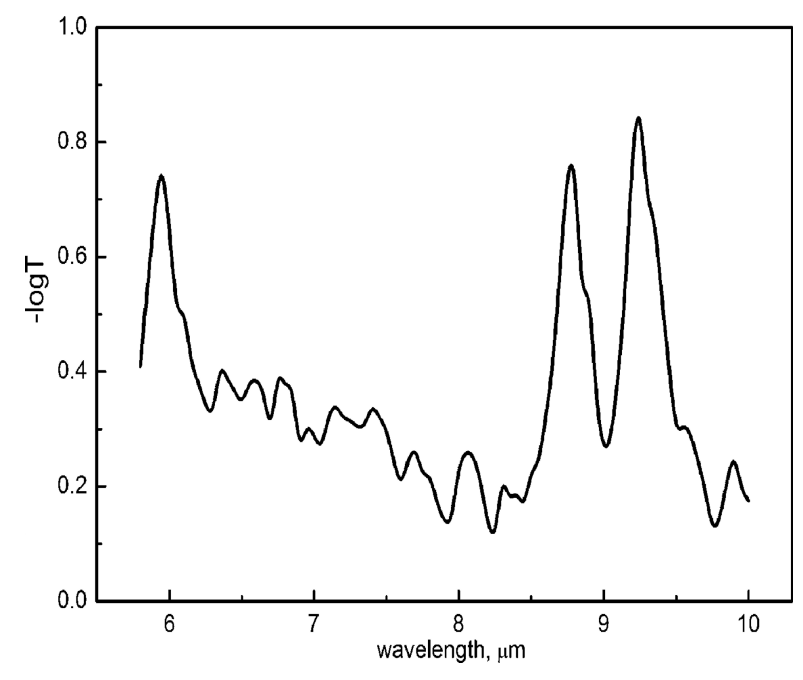

Fig. 4. Remote absorption spectrum of fog comprising a mixture of water with hydroxyalkanes. Fog was kept in the chamber.

\subsection{Atmospheric turbulence effect and detection of variable plumes}

Lidaric measurements are to some degree influenced by outer factors such as fog, precipitation, or the beam path interrupting objects. The manifestations of these factors are rare and obvious, and they can easily be eliminated from the records. But there exists a less obvious factor, atmospheric turbulence, that can permanently worsen the lidar performance.

Turbulence is defined as the nonsystematic motion of air [35]. The steady state wind is not a turbulent motion but the gusts in the wind are. Gusts are accompanied by the stochastic local variations of air density and temperature. The refractive index depends on air density and temperature, so the optical density gradient varies stochastically along the beam path. During propagation the laser beam undergoes chain of random scatterings and refractions. As a result, (i) the radiation spot loses primary integrity, and (ii) the beam propagation direction varies to a small degree. Due to worsening of these beam characteristics, part of the returned radiation misses the lidar collection optics apertures, that is, the photosignal undergoes sequence of permanent random drops.

The turbulence effect reveals itself in the range of a kilometre and more. The irregularity of the lidar return signal depends on the daytime. As an example, the photosignal temporal run of the $8.2 \mu \mathrm{m}$ lidar recorded from the $2.25 \mathrm{~km}$ distant retroreflector is shown in Fig. 3 [14]. The autocorrelation timescales of shown signals are 68 and $25 \mathrm{~ms}$ for the morning and day records, respectively. Obviously the signal in the morning is less noisy than that one hour after midday. The indicator of signal irregularity, the scintillation index $\sigma_{i}^{2}$, was 0.00872 at 6:30 $\mathrm{AM}$ and 0.495 at 1:05 PM, that is, an increase by more than a factor of fifty was observed [14]. When working with the beam path of some kilometres and choosing propitious hours, the daily variation of turbulence has to be taken into account.

One more outer factor in the lidaric detection should be considered. This is the irregularity of the pollutant plume because of random variation of the wind speed and direction. This irregularity reveals itself locally near the pollutant emission source. The release spread is governed by the local wind gusts. On the larger scale more regular wind and more pronounced plume are expected.

The experiment was done with the pollutant release simulation using the fog jet generator. The "Antari" $\mathrm{X} 515 \mathrm{G}$ fog generator was located 5 metres away from the beam path. The sequence of 1-second long fog emissions of the superheated mixture of water with the unspecified hydroxyalkanes was done with the 10seconds period. The reference absorption spectrum of fog shown in Fig. 4 was measured in the cylindrical chamber mounted on the lidar beam path. The cylinder was tightened by the polyethylene film at the ends.

The emission jet contains both fog and vapour fractions of water and hydroxyalkanes. The absorption band centred at $6 \mu \mathrm{m}$ corresponds to water and two bands centred at 8.8 and $9.3 \mu \mathrm{m}$ should be attributed to hydroxyalkanes. Remote spectrum records of the same kind fog obtained in the free release mode are shown in 


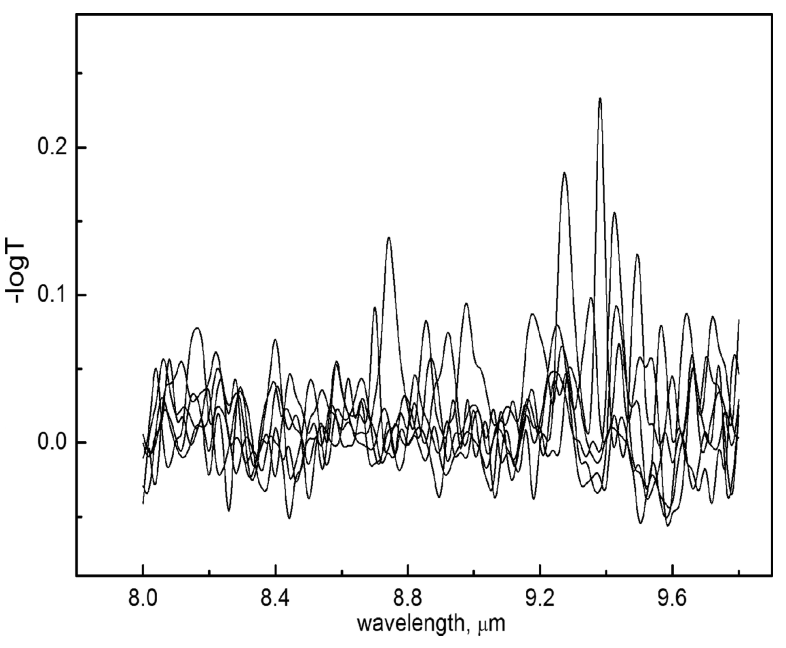

Fig. 5. Remote spectrum records of the water/hydroxyalkanes fog obtained in the free release mode.

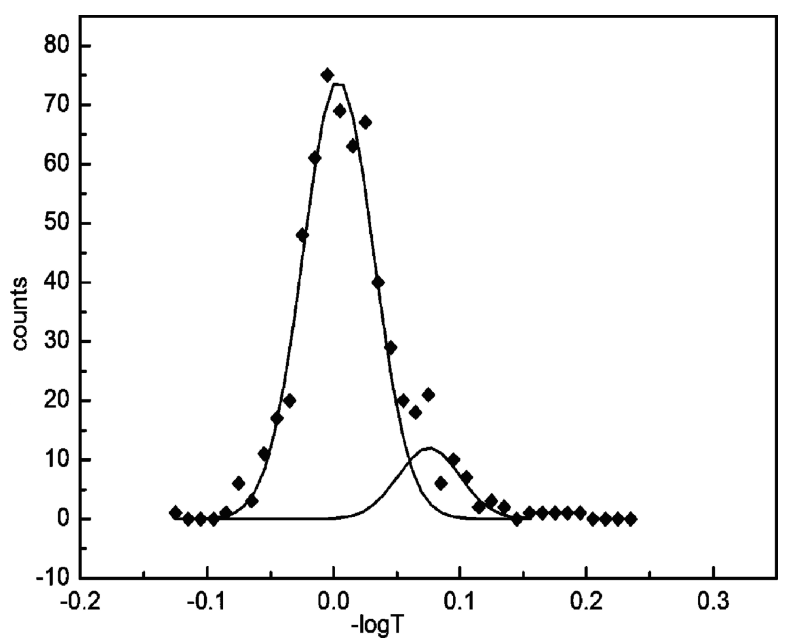

Fig. 6. Histogram of magnitudes of spectral records. Recorded data are least square fitted with two Gaussian functions. The left function centred at 0.0 includes blank records corresponding to no plume on the path. The right function centred at 0.076 includes fog records.

Fig. 5. The $3-6 \mathrm{~m} / \mathrm{s}$ south wind, the $88 \%$ relative humidity and $2{ }^{\circ} \mathrm{C}$ temperature real time data were taken from the internet. The free release records were done in the 8-9.8 $\mu \mathrm{m}$ range.

It should be noted that our developed lidar system has the $10 \mathrm{~Hz}$ pulse repetition rate and this rate is far from the ability to record the plume spectra in the real time. The duration of the $8-9.8 \mu \mathrm{m}$ range scan was $160 \mathrm{~s}$, whereas the plume variation timescale was of the order of seconds. Therefore, the events of the beam crossing by the plume were observed as absorption spikes grouped over the 8.8 and $9.3 \mu \mathrm{m}$ bands. The plume detection events can be processed by probabilistic models. The histogram of fog release spectral records is given in Fig. 6. The histogram comprises two peaks, one located at 0.0 (noise) and the other located at 0.076 (plume). The first peak corresponds to the $\mathrm{H}_{0}$ hypothesis (no plume) and the second peak to the $\mathrm{H}_{1}$ hypothesis (the plume crosses the beam path) [36]. The area of the peak overlap indicates the probability of false alarm [36]. The $2 \%$ false alarm probability follows from the results of the hydroxyalkanes-water fog remote detection. This value is obtained for one absorption spike. If the alarm time tolerance allows, one can use several successive spikes for decision making. For example, the false alarm probability for two successive spikes is $0.02^{2}=0.04 \%$ and that for three spikes is $0.02^{3}=$ $0.0008 \%$.

\section{The environmental protection and industry demands}

\subsection{Measurements in the upper atmosphere}

The lidar has historically been used in the environmental field for measuring criteria pollutants in the upper atmosphere. As the equipment becomes more portable and less expensive, it is gaining acceptance for industrial and commercial applications. The proper detection and identification of chemicals using a differential absorption lidar (DIAL) are directly dependent on it having a unique absorption frequency over the path being measured (i. e. there are no other chemicals present that have the same absorption frequency). In the past, the lack of laser sources that emit specific bands limited the number of chemicals that this technology can identify; however, as more reliable tunable lasers become available, the list of detectable chemicals should increase.

OPO was used in the lidar system developed by Amoruso et al. [12]. A distinctive feature of this system is a narrow bandwidth of the light source. A seed generated by the dye laser was used to achieve the $0.04 \mathrm{~cm}^{-1}$ spectral width in the $1-2 \mu \mathrm{m}$ region. This line width is close to gas absorption line widths under tropospheric conditions. Water vapour concentration was mapped at the $1 \mathrm{~km}$ working distance in the vertical direction. Two wavelengths of 1187.896 and $1187.716 \mathrm{~nm}$ were used for differential absorption measurements.

There are only a few lidar systems that employ MWIR OPO in the troposhperic measurements. One of them was constructed by Fastig et al. [26]. Together with IR DIAL the system included the fluorescence lidar and the aerosol lidar. All three detection modes used the same main mirrors and depending on the mode being used the light was directed to the corresponding detector. Aerosol scattering in the near IR region was 


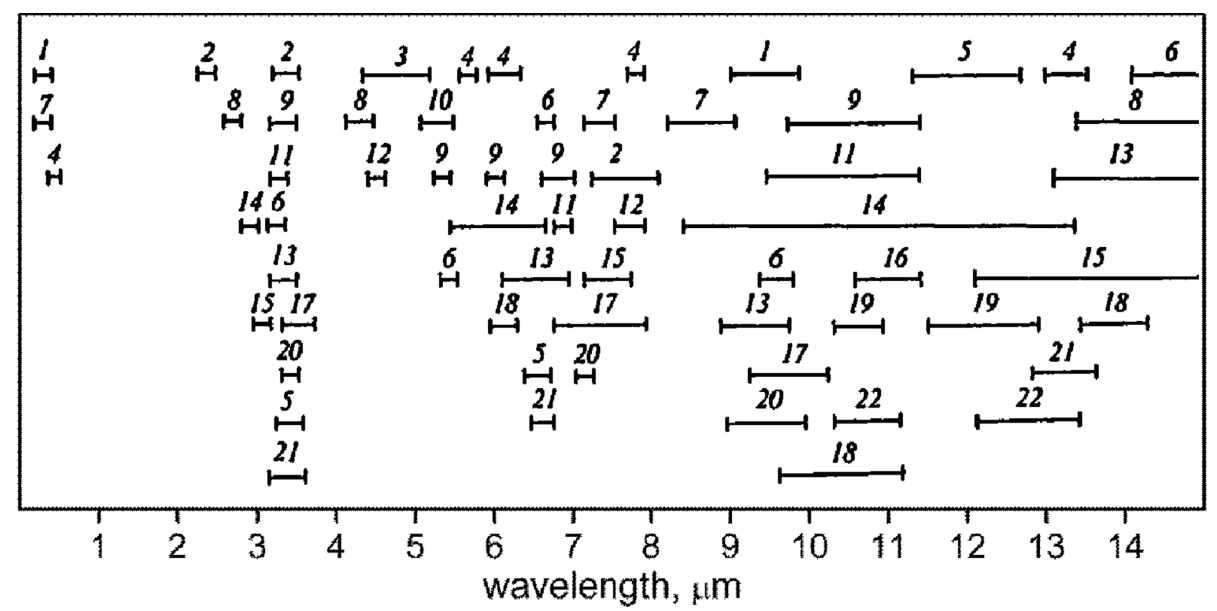

Fig. 7. Positions of absorption bands of atmospheric gases in the spectral range 0.25-15 $\mu \mathrm{m}$ [38]: $\mathrm{O}_{3}(1), \mathrm{CH}_{4}(2), \mathrm{CO}_{(3)}, \mathrm{NO}_{2}(4), \mathrm{C}_{2} \mathrm{H}_{6}(5)$, $\mathrm{C}_{6} \mathrm{H}_{6}(6), \mathrm{SO}_{2}(7), \mathrm{CO}_{2}(8), \mathrm{C}_{3} \mathrm{H}_{6}(9), \mathrm{NO}(10), \mathrm{C}_{2} \mathrm{H}_{4}(11), \mathrm{N}_{2} \mathrm{O}(12), \mathrm{C}_{7} \mathrm{H}_{8}(13), \mathrm{NH}_{3}(14), \mathrm{C}_{2} \mathrm{H}_{2}(15), \mathrm{C}_{4} \mathrm{H}_{6}(16), \mathrm{CH}_{3} \mathrm{OH}(17), \mathrm{C}_{2} \mathrm{H}_{3} \mathrm{Cl}(18)$, $\mathrm{C}_{2} \mathrm{HCl}_{3}(19), \mathrm{C}_{2} \mathrm{H}_{5} \mathrm{OH}(20), \mathrm{C}_{3} \mathrm{H}_{8}(21), \mathrm{C}_{2} \mathrm{CL}_{4}(22)$.

observed and light coming from the topographical object $10 \mathrm{~km}$ away was detected.

\subsection{Urban and land pollution monitoring}

Major pollutants (such as freons, dioxins, $\mathrm{CO}, \mathrm{N}_{2} \mathrm{O}$, VOCs, $\mathrm{CH}_{4}, \mathrm{HCl}, \mathrm{NH}_{3}, \mathrm{SF}_{6}, \mathrm{O}_{3}, \mathrm{C}_{2} \mathrm{H}_{4}, \mathrm{~N}_{2} \mathrm{H}_{4}, \mathrm{CO}_{2}$, $\mathrm{HNO}_{3}$, fuel of missiles, and military toxic gases) display absorption lines that are suitable for application of the DIAL technique in the IR spectral region (Fig. 7) [38].

A typical example of IR DIAL applications possessing a precise selectivity of different interferings was presented in [39]. In this work the concept of a multiwavelength lidar system with multivariate analysing techniques for measuring hydrocarbon gas mixtures has been successfully implemented and tested. The tests were carried out with the light hydrocarbons: methane, ethane, propane, and butane. When larger hydrocarbons such as heptane, hexane, and octane are measured, the spectral overlap will be more severe and it can be difficult to determine the individual concentrations of different hydrocarbons without increasing the number of wavelengths substantially. An examination of the literature indicates that sub-ppm levels of a variety of chemicals in the ranges of one kilometre or more are routine [40]. Table 2 contains detection limits and effective ranges for commonly measured chemicals.

The outstanding example of the OPO based UV/VIS/ IR lidar system was developed by Weibring and Svanberg [41]. The OPO together with second harmonic and difference frequency generation stages allowed covering the $0.22-4.3 \mu \mathrm{m}$ wavelength range. As a result both spatially resolved DIAL and fluorescence lidar modes were implemented. UV DIAL was used to detect $\mathrm{Hg}$ and $\mathrm{SO}_{2}$. Mercury flow from the factory chimney was evaluated to be $6.6 \cdot 10^{-3} \mathrm{~g} / \mathrm{s}$. The flow was mapped in the vertical direction with the working distance of $4 \mathrm{~km}$. The system demonstrated its capability to map the flow and monitor its variation in time. The fluorescence lidar was used both for water and solid state targets. Chlorophyll peak at $685 \mathrm{~nm}$ was detected together with broadband fluorescence radiation from organic materials. Methane, ethane, and propene gases were used for the experiments in the IR region. Background methane concentration of 2 ppm was measured.

\subsection{Detection of pollution sources and industrial product leaks}

DIAL lidars operating in the infrared region have been used to monitor chemical emissions from chemical plants and refineries. Shell Global Systems used a DIAL system to examine fugitive emissions from floating roof storage tanks [42]. In 2006 the Alberta Research Council published the results of a study to demonstrate the applicability of remote sensing technologies to ascertain hydrocarbon emissions at a refinery [43]. The effort involved the use of an infrared imaging camera and a DIAL system. The DIAL system was used to estimate the rate of loss of methane, aliphatic hydrocarbons with two or more carbon atoms $\left(\mathrm{C}_{2+}\right)$, and benzene. The study found that approximately $1240 \mathrm{~kg}$ of $\mathrm{C}_{2+}$ hydrocarbons, $300 \mathrm{~kg}$ of methane, and $5 \mathrm{~kg}$ of benzene were escaping from the refinery every hour. Chambers and Strosher [43] reported on the utility of using DIAL for measuring fugitive emissions from natural gas plants and compared the actual measurements with emission factor estimates. 
Actual emissions were four to eight times higher than values calculated using emission factor estimates.

Other OPO based DIAL systems operating in the MWIR region were built for detection of light hydrocarbons for Phillips Petroleum Co. [44] and Gasprom Russian Joint Stock Co. [45]. The Institut National d'Optique has developed and demonstrated a lidar system for monitoring industrial particulates [46]. The demonstrations were at port facilities where various ores were being unloaded and fugitive dust control was required. The system successfully imaged particulate release and was used to identify and correct loading practices to reduce emissions. The value of the system over high volume stationary air samplers is that it gives real time data of (i) how far particulates are spread from the source, (ii) total average release, and (iii) where "hotspots" are [46]. Heiser and Sedlacek [47] reported on the development of a DIAL to determine the integrity of caps and covers. For wastes capped in place or for older landfills, where a leachate collection system is absent and there is no generation of methane gas, the authors propose injecting a perfluorocarbon tracer into the capped area and using the open path lidar to determine if any of the gas escapes.

A demonstration of the ability of airborne DIAL to detect gas leaking from underground pipelines is presented in [48]. The airborne natural gas emission lidar (ANGEL) system operates from a fixed-wing aircraft. It has two DIAL lasers tuned to detect methane and ethane. The system has a scanning component that is pre-programmed with the pipeline location data showing the exact location of any gas leaks and an estimate of their concentration. A portable and less complex system was also tested [49]. This system, which can be mounted on the undercarriage of a helicopter, consists of a methane-detecting DIAL, digital imaging camera, and GPS unit.

A compact mid-infrared DIAL named Lidar II was created by LaSen Inc company for ground-based and airborne monitoring of leaks in natural gas pipeline systems [?]. It can be used on the ground in a topographic mode or in a look-down mode from a helicopter platform. The sensor operates in the intracavity OPO mode continuously tunable in the $3.2-3.45 \mu \mathrm{m}$ range with the maximum spectral resolution of $2 \mathrm{~cm}^{-1}$. The primary focus of the device was directed on hydrocarbons and volatile organics and to determine the feasibility of the sensor for standoff detection of aerosolized biological warfare agents.

\section{Concluding remarks}

In this paper we described how the infrared differential absorption lidar techniques can be applied in solution of industry and environmental tasks. The combination of high power and high monochromacity, specific modulation techniques, and long path permits extreme sensitivities of this method. However, in future developments, higher sensitivity and selectivity are needed for monitoring the pollutant background concentration. A progress can be achieved by the development of new laser sources and detectors operating in the LWIR region (so-called "fingerprint" region), where the molecular absorption strengths are the highest. To achieve better results it is important to create compact millijoule pulse energy continuously tunable MWIR and LWIR sources with a high pulse repetition rate. Resolving of the exposed problems will allow creation of a smarter remote monitoring equipment with the acceptably small detection limits and low false alarm probabilities.

\section{References}

[1] R.A. Baumgartner and R.L. Byer, Continuously tunable IR lidar with applications to remote measurements of $\mathrm{SO}_{2}$ and $\mathrm{CH}_{4}$, Appl. Opt. 17, 3555-3561 (1978).

[2] R.M. Measures, Laser Remote Sensing. Fundamentals and Applications (Krieger, Malabar, Florida, 1992).

[3] A. Clericetti, B. Calpini, E. Durieux, H. van den Bergh, and M.J. Rossi, Pump-and-probe lidar for in-situ probing of atmospheric chemistry, Proc. SPIE 1714, 291302 (1992).

[4] D.R. Pendleton, Air toxics: Sources and monitoring in Texas, Environ. Health Perspect. Suppl. 103(S6), 223228 (1995).

[5] R.J. Hogan, A.J. Illingworth, E.J. O'connor, and J.P.V.P. Baptista, Characteristics of mixed-phase clouds. II: A climatology from ground-based lidar, Quart. J. Roy. Meteorolog. Soc. 129, 2117-2134 (2003).

[6] A. Chambers, Optical Measurement Technology for Fugitive Emissions from Upstream Oil and $\mathrm{Gas} \mathrm{Fa-}$ cilities, Alberta Research Council Report, Project No. CEM - P004.03 (2004).

[7] D.G. Murdock, S.V. Stearns, R.T. Lines, D. Lenz, M.D. Brown, and C.R. Philbrick, Applications of realworld gas detection: Airborne Natural Gas Emission Lidar (ANGEL) system, J. Appl. Remote Sensing 2, 023518 (2008).

[8] M.B. Frish, M.A. White, and M.G. Allen, Handheld laser-based sensor for remote detection of toxic and hazardous gases, Proc. SPIE 4199, 19-28 (2001). 
[9] R. Vanderbeek and K. Gurton, Backscatter measurements of aerosolized CB simulants with a frequency agile $\mathrm{CO}_{2}$ lidar, Proc. SPIE 5268, 184-193 (2004).

[10] Laser Based Stand-Off Detection of Biological Agents, NATO RTO, Final Report of Task Group SET098/RTG-55 (2010).

[11] V. Vaičikauskas, M. Kaučikas, and V. Švedas, Mobile spectroscopic system for trace gas detection using a tunable mid-IR laser, Rev. Sci. Instrum. 78, 023106 (2007).

[12] S. Amoruso, A. Amodeo, M. Armenante, A. Bosellid, L. Mona, M. Pandolfi, G. Pappalardo, R. Velottad, N. Spinelli, and X. Wang, Development of a tunable IR lidar system, Optics Lasers Eng. 37, 521-532 (2002).

[13] M. Taslakov, V. Simeonov, and H. van den Bergh, Open path atmospheric spectroscopy using room temperature operated pulsed quantum cascade laser, Spectrochim. Acta A 63, 1002-1008 (2006).

[14] W.W. Harper, J.D. Strasburg, P.M. Aker, and J.F. Schultz, Remote Chemical Sensing Using Quantum Cascade Lasers, Pacific Northwest National Laboratory Report PNNL-14525 (Richland, Washington 99352, USA, 2004).

[15] K. Miyamoto and H. Ito, Wavelength-agile midinfrared $(5-10 \mu \mathrm{m})$ generation using a galvanocontrolled KTiOPO4 optical parametric oscillator, Opt. Lett. 32, 274-276 (2007).

[16] M. Henriksson, M. Tiihonen, V. Pasiskevicius, and F. Laurell, $\mathrm{ZnGeP}_{2}$ parametric oscillator pumped by a linewidth-narrowed parametric $2 \mu \mathrm{m}$ source, Opt. Lett. 31, 1878-1880 (2006).

[17] S. Haidar, K. Miyamoto, and H. Ito, Generation of tunable mid-IR $(5.5-9.3 \mu \mathrm{m})$ from a $2 \mu \mathrm{m}$ pumped $\mathrm{ZnGeP}_{2}$ optical parametric oscillator, Opt. Commun. 241, 173-178 (2004).

[18] K.L. Vodopyanov and P.G. Schunemann, Broadly tunable noncritically phase-matched $\mathrm{ZnGeP}_{2}$ optical parametric oscillator with a $2-\mu \mathrm{J}$ pump threshold, Opt. Lett. 28, 441-443 (2003).

[19] T. Schroeder, Two-stage nanosecond OPO based on $\mathrm{LiNbO}_{3}$ and $\mathrm{AgGaSe}_{2}$ tunable from $3 \mu \mathrm{m}$ to $6 \mu \mathrm{m}$, in: Lasers and Electro-Optics, 2001, CLEO'01, Technical Digest, Summaries of papers presented at the conference (IEEE, 2002) pp. 450-451.

[20] E. Cheung, S. Palese, H. Injeyan, C. Hoefer, R. Hilyard, H. Komine, J. Gish, and W. Bosenberg, High power optical parametric oscillator source, in: Proceedings of IEEE Aerospace Conference, Vol. 3 (2000) pp. 55-59.

[21] H. Komine, J.M. Fukumoto, W.H. Long, and E.A. Stappaerts, Noncritically phase matched midinfrared generation in $\mathrm{AgGaSe}_{2}$, IEEE J. Sel. Topics Quant. Electron. 1, 44-49 (1995).

[22] T. Chuang and R. Burnham, Multiple mid-infrared generation using PPLN and $\mathrm{AgGaSe}_{2}$ OPOs, in: Lasers and Electro-Optics, 1998, CLEO 98, Technical Di- gest, Summaries of papers presented at the Conference (IEEE, 2002) pp. 541-542.

[23] Y. Isyanova, A. Dergachev, D. Welford, and P.F. Moulton, Multi-wavelength, 1.5-10 $\mu \mathrm{m}$ tunable, tandem OPO, in: Advanced Solid State Lasers, eds. M. Fejer, H. Injeyan, and U. Keller, Vol. 26 of OSA Trends in Optics and Photonics (Optical Society of America, 1999), paper WB4.

[24] S. Chandra, T. Allik, G. Catella, R. Utano, and J. Hutchinson, Continuously tunable, 6-14 $\mu \mathrm{m}$ silvergallium selenide optical parametric oscillator pumped at $1.57 \mu \mathrm{m}$, Appl. Phys. Lett. 71, 584-586 (1997).

[25] Y. Ehrlich, S. Pearl, G. Peleg, and S. Fastig, High brightness tunable OPO source for 8-12 $\mu \mathrm{m}$ dial, in: 22nd International Laser Radar Conference, eds. G. Pappalardo and A. Amodeo (ESA, Paris, 2004) p. 191.

[26] S. Fastig, Y. Ehrlich, S. Pearl, E. Naor, Y. Kraus, T. Inbar, and D. Katz, Multi-spectral lidar system - design, build and test, in: 23rd International Laser Radar Conference, eds. C. Nagasawa and N. Sugimoto (2006) pp. 20-27.

[27] J.M. Fukumoto, W. Katata, E.J. Griffin, C.R. Swim, and J.A. Fox, All solid-state, 8-12 $\mu \mathrm{m}$ continuously tunable DIAL laser transmitter with patterncontrollable, rapid wavelength switching, in: Advanced Solid-State Photonics, ed. J. Zayhowski (OSA, 2003) paper 131.

[28] P.B. Phua, K.S. Lai, R.F. Wu, and T.C. Chong, Higheffciency mid-infrared $\mathrm{ZnGeP}_{2}$ optical parametric oscillator in a multimode-pumped tandem optical parametric oscillator, Appl. Optics 38, 563-565 (1999).

[29] G. Rustad, S. Nicolas, O. Nordseth, and G. Arisholm, High pulse energy mid-infrared laser source, Proc. SPIE 5989, 598904 (2005).

[30] R.E. Warren and R.G. Vanderbeek, Detection and classification of atmospheric aerosols using multiwavelength $\mathrm{CO}_{2}$ lidar, Proc. SPIE 6554, 65540V (2007).

[31] R.E. Warren and R.G. Vanderbeek, Parallel estimation of path-integrated concentration and vapor absorptivity using topographic backscatter lidar, Proc. SPIE 5887, 58870Q (2005).

[32] Testing and Evaluation of Standoff Chemical Agent Detectors, National Research Council, Committee on Testing and Evaluation of Standoff Chemical Agent Detectors (The National Academies Press, Washington, USA, 2003).

[33] T. Iseki, H. Tal, and K. Kimura, A portable remote methane sensor using a tunable diode laser, Meas. Sci. Technol. 11, 594-602 (2000).

[34] List of Extremely Hazardous Substances and Data for Hazards Analysis (Exhibit C), in: Technical Guidance for Hazards Analysis. Emergency Planning for Extremely Hazardous Substances, U.S. Environmental Protection Agency, Federal Emergency Management 
Agency, U.S. Department of Transportation, December 1987, pp. C2-C11.

[35] Atmospheric Transmission, Emission and Scattering, ed. T.G. Kyle (Pergamon Press, Oxford, New York, Seoul, Tokyo, 1991).

[36] G.R. Osche, Optical Detection Theory for Laser Applications (Wiley, New York, 2002)

[37] R. Mezheris, Laser Remote Sounding (Mir, Moscow, 1987) [in Russian].

[38] P. Weibring, C. Abrahamsson, M. Siöholm, J.N. Smith, H. Edner, and S. Svanberg, Multi-component chemical analysis of gas mixtures using a continuously tuneable lidar system, Appl. Phys. B 79, 525-530 (2004).

[39] Open Path Technologies: Measurement at a Distance. Lidar, http://clu-in.org/programs/21m2/openpath/ lidar/\#chemical .

[40] P. Weibring and S. Svanberg, Versatile mobile lidar system for enviromental monitoring, Appl. Opt. 42, 3583-3594 (2003).

[41] S. O'Connor, H. Walmsley, and H. Pasley. Differential absorption LIDAR (DIAL) measurements of the mechanisms of volatile organic compound loss from external floating roofed tanks, Proc. SPIE 3493, 255-266 (1998).

[42] A. Chambers and M. Strosher, Refinery Demonstration of Optical Technologies for Measurement of Fugitive Emissions and for Leak Detection (Alberta Research Council Inc., 2006).
[43] A.R. Geiger and S.N. Prasad, Mid-infrared DIAL lidar for petroleum exploration and pipeline monitoring, Proc. SPIE 2374, 240-248 (1995).

[44] P.G. Philippov, Yu.A. Bakhirkin, V.N. Moiseev, R.N. Pichtelev, S.N. Gurkin, and I.A. Zhutchenko, DIAL infrared lidar for monitoring of main pipelines and gas industry objects, Proc. SPIE 3504, 119-127 (1998).

[45] B. Belanger, A. Fougeres, M. Talbot, and J. Cormier, Industrial site particulate pollution monitoring with an eye-safe and scanning industrial fiber lidar, Proc. SPIE 4199, 67-76 (2000).

[46] J. Heiser and A. Sedlacek, Using LIDAR to measure perflurocarbon tracers for the verification and monitoring of cap and cover systems, Water Air Soil Pollut. 170, 345-357 (2006).

[47] Flight Testing of an Advanced Airborne Natural Gas Leak Detection System, Final Report, ITT Industries Space Systems (Rochester, NY, USA, 2005), www.netl.doe.gov/technologies/oil-gas/publications/ $\mathrm{td} / 41877$ final.PDF

[48] U.S. DOE, Field testing of remote sensor gas leak detection systems, Rocky Mountain Oilfield Testing Center (RMOTC, Casper, WY, 2004).

[49] A.E. Degtiarev, A.R. Geiger, and R.D. Richmond, Compact mid-infrared DIAL lidar for ground-based and airborne pipeline monitoring, Proc. SPIE 4882, 432-441 (2003).

\title{
INFRARAUDONŲJŲ LIDARINIŲ ATMOSFEROS JUTIKLIŲ PRITAIKYMAS APLINKOSAUGOS IR PRAMONĖS POREIKIAMS
}

\author{
V. Švedas ${ }^{\text {a }}$, V. Vaičikauskas ${ }^{\text {a }}$, M. Kaučikas ${ }^{b}$ \\ ${ }^{a}$ Fizikos institutas, Fiziniu ir technologijos mokslu centras, Vilnius, Lietuva \\ ${ }^{\mathrm{b}}$ UAB EKSPLA, Vilnius, Lietuva
}

\begin{abstract}
Santrauka
Aptariami atmosferos taršos stebėsenos infraraudonosios srities lidarais ịrangos ir metodologiniai aspektai, o taip pat optinių parametrinių osciliatorių (tame tarpe mūsų dvipakopès konversijos sistemos), veikiančių molekulių fundamentinių virpesių srityje, ypatumai. Nagrinejjami aplinkosaugos ir pramonès poreikiai ir techniniai reikalavimai šiai nuotolinei technologijai. Nežiūrint pažangos šioje srityje ir pasiektų žemų detektavimo slenksčių, dar neįmanoma vienareikšmiškai ir greitai identifikuosi patekusius teršalus. Tiriami detektavimo charakteristikas bloginantys vidiniai ir išoriniai veiksniai, tokie kaip siunčiamo impulso energijos nestabilumas, atmosferos turbulentiškumas ir vèjo gūsių keliamas teršalo pliūpsnių ne-
\end{abstract}

taisyklingas pasklidimas. Pateikiamas lidarinio matavimo modelis, atsižvelgiantis į spinduliuotès impulse nestabilumą. Modelis pritaikytas 8-14 $\mu \mathrm{m}$ srities ir 0,5 mJ impulso energijos lidarui, matuojančiam topografinio taikinio metodu $0,05 \mathrm{~m}^{2}$ teleskopu ir gyvsidabrio kadmio telūrido fotodetektoriumi. Nustatyta, kad lazerio impulse nestabilumas, charakterizuojamas energijos dispersija $D$, iš esmès pablogina detektavimo slenksčio vertes dirbant mažesniais atstumais $(<2 \mathrm{~km}$, kai $D=1 \%)$. Eksperimentiškai išbandyta lidaro adaptacija detektuojant greitai kintančius ir netaisyklingus teršalo simulianto pliūpsnius. Sklindančiu pliūpsnių susikirtimo su lidaro spinduliu atvejams pritaikytas tikimybinis modelis, leidžiantis įvertinti klaidingo aliarmo tikimybę. 